\title{
REVIEW \\ Feeding children with cerebral palsy and swallowing difficulties
}

\author{
JC Arvedson
}

Children with cerebral palsy (CP) are at risk for aspiration with oral feeding with potential pulmonary consequences, and commonly have reduced nutrition/hydration status and prolonged stressful meal times. There is considerable variability in the nature and severity of swallowing problems in these children whose needs change over time. Children with generalized severe motor impairment (for example, spastic quadriplegia) are likely to experience greater swallowing deficits than those with diplegia, but oropharyngeal dysphagia is prevalent even in children with mild CP. This review is focused on dysphagia in children with CP: types of deficits, clinical and instrumental evaluation, management decision making and evidence of effectiveness of interventions.

European Journal of Clinical Nutrition (2013) 67, S9-S12; doi:10.1038/ejcn.2013.224

Keywords: cerebral palsy; dysphagia; pediatrics; feeding; swallowing

\section{INTRODUCTION}

Children with cerebral palsy (CP) commonly have feeding disorders and swallowing problems (dysphagia) that in many instances place them at risk for aspiration with oral feeding, with potential pulmonary consequences. They also commonly have reduced nutrition/hydration status and prolonged stressful meal times. The specific nature and severity of the swallowing problems may differ, at least to some degree, in relation to sensorimotor impairment, gross and fine motor limitations, and cognitive/ communication deficits. Children with generalized severe motor impairment (for example, spastic quadriplegia) are likely to experience greater swallowing deficits ${ }^{1,2}$ than those with diplegia, but oropharyngeal dysphagia is prevalent even in children with mild CP. ${ }^{3}$ Concerns are multifactorial and include issues of reduced volume of food and liquid consumed orally, nutrition deficits, inadequate hydration and limited range of textures with slow advance of oral skills.

Children with moderate-to-severe dysphagia usually are managed most effectively with an interdisciplinary team that allows for multiple factors to be addressed in a coordinated way. These factors include, but are not limited to, gastrointestinal issues, pulmonary status, nutrition/hydration, oral sensorimotor skills, behavioral issues and family interactions. The importance of a structured approach is stressed to handle these multiple problems. ${ }^{4}$ It is critical that all decisions for the management of feeding and swallowing problems are made in consideration of the primary needs of the child that is, a stable airway with adequate nutrition and hydration. In addition, any feeding/ swallowing intervention should be pleasurable and non-stressful for patients and care givers. In some instances, tube feeding may be needed either temporarily or long term..$^{5-8}$ It is expected, with rare exceptions, that these children can cope with at least minimal tastes for pleasure, a practice that may have a positive impact on management of saliva/secretions while maintaining oral function and swallowing.

This review paper is focused on dysphagia: types of deficits, clinical and instrumental evaluation, management decision making and evidence of effectiveness of interventions for children with $\mathrm{CP}$.

\section{TYPES OF SWALLOWING AND FEEDING PROBLEMS IN CHILDREN WITH CP}

Oropharyngeal dysphagia may be characterized by problems in any or all phases of swallowing ${ }^{9,10}$ (Table 1). The types of oral and pharyngeal problems that children with $\mathrm{CP}$ have include reduced lip closure, poor tongue function, tongue thrust, exaggerated bite reflex, tactile hypersensitivity, delayed swallow initiation, reduced pharyngeal motility and drooling. Impaired oral sensorimotor function can result in drooling that in turn results in impaired hydration. ${ }^{11}$ Problems with liquids are common and usually relate to a timing deficit with delayed pharyngeal swallow initiation. Problems with thick smooth, lumpy or mashed foods relate to residue in the pharynx when pharyngeal motility is reduced. Residue can spill into the open airway after swallows. Children may appear to handle thicker food and liquid more easily, as they have more time to initiate a swallow, but not in all instances. It is not possible to define pharyngeal physiology of swallowing by clinical feeding/swallowing evaluations or simply by observation of children while they are eating and drinking. The bolus size can be manipulated for safety in some children. Small boluses are easier for many children than large ones, although the opposite may be true for others. Children with $\mathrm{CP}$ frequently need more time to complete feeding tasks, but caution is urged as fatigue may become a factor, as well as reduced attention to the task. Meal times longer than $30 \mathrm{~min}$, on a regular basis, often signal a feeding/swallowing problem.

Feeding disorders may present as inadequate growth, prolonged feeding times, delayed progression of oral feeding skills and/or recurrent respiratory disease. Children with $\mathrm{CP}$ have dysphagia caused by a central nervous system disorder in which passive tone is variable (hypertonia common with spastic $(\mathrm{P})$ ), active tone is normal or mildly decreased and primitive reflexes may be strong and persistent. Although children with neurological-based dysphagia may not produce a gag upon stimulation, they may be appropriate for oral feeding. There is no direct relationship between gag and swallowing ability.

Chronic aspiration is of concern in this patient group and may be difficult to delineate when there is no cough response to aspiration events. ${ }^{12}$ Hypoxemia may occur during oral feeding. ${ }^{13}$ 
Table 1. Oropharyngeal dysphagia: processes and problems by phase of swallowing

\begin{tabular}{|c|c|c|}
\hline $\begin{array}{l}\text { Phase of } \\
\text { swallowing }\end{array}$ & Processes in brief & Possible problems (not intended to be all inclusive list) \\
\hline $\begin{array}{l}\text { Bolus } \\
\text { formation }\end{array}$ & $\begin{array}{l}\text { Getting food into mouth, manipulating via lip closure, jaw } \\
\text { stability, tongue action, getting ready to propel food or liquid } \\
\text { over tongue posteriorly }\end{array}$ & $\begin{array}{l}\text { Loss of food from mouth; material in anterior or lateral sulcus; } \\
\text { limited or immature chewing; limited tongue action }\end{array}$ \\
\hline Oral transit & $\begin{array}{l}\text { Moving material through oral cavity (mouth) into pharynx } \\
\text { (throat) }\end{array}$ & $\begin{array}{l}\text { Initial tongue motion is forward resulting in spillage from the } \\
\text { mouth; delayed initiation of posterior tongue propulsion }\end{array}$ \\
\hline $\begin{array}{l}\text { Pharyngeal } \\
\text { phase } \\
\text { initiation }\end{array}$ & $\begin{array}{l}\text { Involving critical timing of tongue propulsion and closure of } \\
\text { airway }\end{array}$ & $\begin{array}{l}\text { Material in valleculae more than } 1 \mathrm{~s} \text { and/or into pyriform } \\
\text { sinuses before swallow initiation; material on tonsil tissue or } \\
\text { posterior pharyngeal wall (PPW) }\end{array}$ \\
\hline $\begin{array}{l}\text { Pharyngeal } \\
\text { phase }\end{array}$ & $\begin{array}{l}\text { Involving active coordinated strong muscle function of tongue } \\
\text { base, pharyngeal constrictors, and PPW, to move material } \\
\text { through pharynx into upper esophagus sphincter (UES) }\end{array}$ & $\begin{array}{l}\text { Reduced airway closure resulting in aspiration, especially with } \\
\text { thin liquid; residue in pharynx with reduced muscle strength, } \\
\text { usually thick food; pharyngonasal backflow; reduced UES } \\
\text { opening }\end{array}$ \\
\hline $\begin{array}{l}\text { Upper } \\
\text { esophageal } \\
\text { phase }\end{array}$ & $\begin{array}{l}\text { Opening of UES by anterior \& superior movement of } \\
\text { hyolaryngeal complex; peristaltic action to move bolus on } \\
\text { down through esophagus }\end{array}$ & $\begin{array}{l}\text { Reduced UES opening; reduced duration of UES opening; } \\
\text { cricopharyngeal bar that may or may not inhibit bolus transit; } \\
\text { peristaltic action moves bolus on down through esophagus }\end{array}$ \\
\hline
\end{tabular}

Table 2. Key questions to ask parents that may reveal the need for possible assessment of feeding/swallowing problems in children with cerebral palsy

\begin{tabular}{ll}
\hline Questions & Red flags \\
\hline How long does it take to feed your child? & More than 30 min, on any regular basis \\
Are meal times stressful to child or parent? & Yes, if one or other, or both \\
Is your child gaining weight adequately? & Lack of weight gain over 2-3 months in young child, not just weight loss \\
Are there signs of respiratory problems? & Increased congestion at meal times, 'gurgly' voice, respiratory illnesses \\
\hline
\end{tabular}

The risk of aspiration in children with CP can decrease over time as developmental gains are made, although it is not unusual for children to show increased signs of dysphagia as they reach puberty, at which time changes in nutritional needs occur as well as possible increased scoliosis or kyphosis. Further, the risks of aspiration complications are dependent partially on the initial condition of the child.

\section{KEY QUESTIONS TO ASK PARENTS TO ASSIST IN THE DETERMINATION OF NEED FOR COMPREHENSIVE EVALUATION}

Four questions will yield pertinent information from parents that can aid in directing next steps in decision making for evaluation and management by physicians, nurses and/or therapists. These questions cover major areas of potential deficits (Table 2) to provide a basis for further investigation. They do not necessarily define the specific problems. A feeding time of $>30 \mathrm{~min}$ and/or absence of weight gain for 2-3 months could be a sign of a problem in young children, particularly in the first 2 years of life. Stressful mealtimes are likely to exacerbate feeding/swallowing problems and can cause further stress to care givers and children. A gurgly voice quality indicates secretions in the laryngeal vestibule that could be aspirated and contribute to respiratory problems. Clearly, a history of respiratory illnesses that could be related to oral feeding requires in-depth exploration.

\section{CLINICAL FEEDING EVALUATION}

The clinical feeding evaluation offers the opportunity to observe children at mealtime settings. One can describe oral sensorimotor deficits, but pharyngeal swallow status can only be inferred from a clinical evaluation. It is highly likely that both sensory and motor deficits occur, although not always in equal proportion. All cranial nerves involved in swallowing have sensory and motor innervation, except cranial nerve XII that provides motor innervation only to intrinsic muscles of the tongue. Mixed textures, such as pasta pieces in liquid, tend to be difficult to manage for all children. Children with primarily oral sensory disorders may hold food under the tongue to avoid swallowing. If they vomit, they are likely to vomit only certain textures. In contrast, children with primarily oral motor problems may be unable to hold and manipulate food on the tongue; therefore, food may fall out of the mouth. Their vomiting is not likely to be texture specific. Children with major oral sensory problems will put their own fingers or toys in their mouth but usually will not accept oral stimulation by others. They often reject tooth brushing, whereas children with motor disorders usually will tolerate tooth brushing. Children with immature feeding skills may be easier to manage than those with abnormal patterns. However, it is common for children with $\mathrm{CP}$ to have both patterns.

\section{INSTRUMENTAL EVALUATION OF SWALLOWING}

Criteria for an instrumental swallowing study in children with $\mathrm{CP}$ include the following: (1) risk of aspiration (by history or observation), (2) prior aspiration pneumonia, (3) suspicion of a pharyngeal or laryngeal problem (for example, breathy or husky voice quality), (4) gurgly voice quality. A Videofluoroscopic Swallow Study (VFSS) provides dynamic visualization of oral, pharyngeal and upper esophageal phases of swallowing. A flexible endoscopic evaluation of swallowing (FEES) allows direct visualization of some aspects of the pharyngeal phase. ${ }^{14}$ FEES is useful in selected instances, particularly with concerns related to possible upper airway obstruction and/or vocal fold paresis or paralysis. Advantages of FEES include the absence of radiation as well as the possibility to do bedside examinations, to evaluate handling of secretions and to do sensory testing. FEES does not always delineate aspiration events. Each examination is a 'brief window in time' and does not therefore represent a typical meal. Overall, agreement of findings between VFSS and FEES is low. ${ }^{15}$ Pharyngeal residue is perceived greater on FEES than from VFSS. ${ }^{16}$ However, VFSS allows visualization of all phases of swallowing, which makes that study more comprehensive in most instances. 


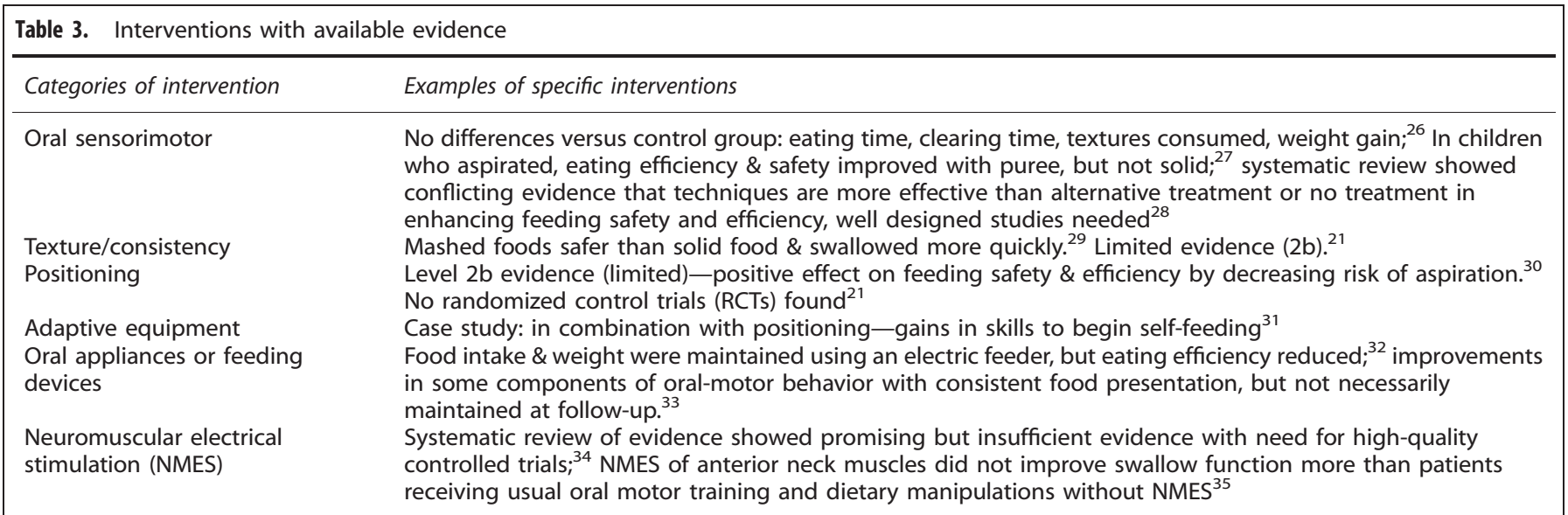

\section{MANAGEMENT DECISION MAKING}

Management decision making must take into account all interrelated factors and not simply therapeutic programs to advance oral skills. Children vary from day to day and over the course of a day, which complicates decision making for precise recommendations. Children may appear safe for oral feeding at some times but not at others. Factors that may have a negative impact include, but are not limited to, fatigue, lethargy and seizure disorder. Individual decision making with close monitoring over time is critical as children show changes in oral skills and safety of swallowing.

Total oral feeding is not a realistic goal for all children with CP but the aim should be to introduce some feeding that is physiologically possible and fits in with the social situation of the child and his/her family. The highest priorities are always adequate health status, particularly nutrition/hydration and pulmonary function.

\section{FEEDING/SWALLOWING INTERVENTIONS: EVIDENCE OF EFFECTIVENESS \\ General guidance}

It is critical that feeding/swallowing teams include dietitians who make recommendations regarding nutrition and hydration, growth patterns, allergies or food sensitivities that could have an impact on intervention(s) aimed at oral skills and swallowing. The child should take part in family meal times, even if not fed orally. It is important to consider sensory responses when planning intervention(s), not only motor aspects. Non-nutritive oral opportunities are thought to facilitate oral feeding skills, for example, sucking opportunities for preterm infants, most often via pacifier. ${ }^{17-19}$ Older children who are not safe to take nutrition orally can be given opportunities to mouth toys or to put their fingers into food and suck on their fingers with a miniscule amount of food on them, and to accept two to three drops of water via a spoon. It is rare that a child cannot take anything orally (nil by mouth). However, it is important that children are not put at risk for aspiration. Gastrostomy tube feedings may improve growth, especially with severely affected gross motor function and those children who have had poor weight gain along with their severe feeding and swallowing problems. ${ }^{20}$

\section{Evidence-based interventions}

It would seem logical that feeding and swallowing interventions lead to benefits, which are measurable and objective. However, the current level of evidence is poor ${ }^{21}$ with limited information regarding outcomes (Table 3). Empirical data are needed. Randomized controlled trials for intervention are extraordinarily difficult to carry out. Snider et al. ${ }^{21}$ found only five randomized controlled trials in their review of 12 electronic databases. Feeding safety and efficiency were primary outcomes in some studies, height and weight changes in others. Oral sensorimotor interventions were compared in two studies involving children with CP. ${ }^{22}$ They found it impossible to compare as these treatments used different approaches with different durations and intensity. Oral feeding interventions for children with CP may promote oral motor function, but these interventions have not been shown to be effective in promoting feeding efficiency or weight gain. ${ }^{23}$ Scianni et al. ${ }^{24}$ examined muscle strengthening in children and adolescents with $\mathrm{CP}$ (which did not include oral motor muscles), and suggested that strengthening interventions are neither effective nor worthwhile. Although it is not possible to directly correlate approaches to interventions across body systems, these findings suggest that techniques that propose to strengthen the lip, tongue and jaw muscles that are often included in oral-motor therapy should be critically evaluated. Similarly, data at higher levels of evidence than case studies or case series are needed for all types of interventions. ${ }^{25}$

Opportunities for production of purposeful swallows are important for oral skill development and for pleasure. Stimulation with 'tastes' can be part of the daily routine for children with $\mathrm{CP}$, with rare exceptions. Children receiving nutrition and hydration via tube should be appropriate for brief 'taste' sessions over 2-5 min multiple times per day.

Spoon presentations with a very small amount of water or flavored water may be tolerated without compromising pulmonary status. A few drops of lemon juice or ice water via spoon may be appealing to stimulate swallowing and to give pleasure without increasing risk for aspiration and its consequences. Regular and thorough oral care is vital for all children. All of these suggestions need validation (or refutation) with systematic data collection.

In summary, children with $\mathrm{CP}$ present with a wide range of feeding and swallowing problems that need to be scrutinized comprehensively and monitored over time. All children deserve opportunities for oral feeding to whatever extent is possible in light of pulmonary status and oropharyngeal skill levels, in developmentally appropriate ways. It is hoped that all oral taste and feeding experiences are non-stressful for children and their parents. No matter how much care givers and therapists want children to be total oral feeders, nutrition and hydration needs should always take top priority. Children must be well nourished in order to maximize global developmental function and overall health (where possible).

This supplement is provided as a professional service by the Paediatric Division of Nutricia Advanced Medical Nutrition. 


\section{CONFLICT OF INTEREST}

JCA has received consulting fees from UL Verification Service Inc and Lecture fees from Education Resources, Inc.

\section{REFERENCES}

1 Calis EA, Vengelers R, Sheppard JJ, Tibboel D, Evenhuis HM, Penning C. Dysphagia in children with severe generalized cerebral palsy and intellectual disability. Dev Med Child Neurol 2008; 50: 625-630.

2 Parkes J, Hill N, Platt MJ, Donnelly C. Oromotor dysfunction and communication impairments in children with cerebral palsy: a register study. Dev Med Child Neuro 2010; 52: 1113-1119.

3 Benfer KA, Weir KA, Bell KL, Ware RS, Davies PSW, Boyd RN. Oropharyngeal dysphagia and gross motor skills in children with cerebral palsy. Pediatrics 2013 131: e1553-e1562.

4 Schwarz ST, Corredor J, Fisher-Medina J, Cohen J, Rabinowitz S. Diagnosis and treatment of feeding disorders in children with developmental disabilities. Pediatrics 2001; 108: 671-676.

5 Angharad V-R, Wells J, Grant $\mathrm{H}$, Alder N, Vadamalayan B, Eltumi $\mathrm{M}$ et al. Gastrostomy feeding in cerebral palsy: enough and no more. Dev Med Child Neurol 2010; 52: 1099-1105.

6 Dahlseng MO, Andersen GL, DA, Graca Amdrada M, Arnaud C, Balu R, De la Cruz J et al. Gastrostomy tube feeding of children with cerebral palsy: variation across six European countries. Dev Med Child Neurol 2012; 54: 938-944.

7 Sleigh G, Brocklehurst P. Gastrostomy feeding in cerebral palsy: a systematic review. Arch Dis Child 2004; 89: 534-539.

8 Sleigh G, Sullivan PB, Thomas AG. Gastrostomy feeding versus oral feeding alone for children with cerebral palsy. Cochrane Database Syst Rev 2004; 2: CD003943.

9 Arvedson JC, Brodsky L (eds) Pediatric Swallowing and Feeding: Assessment and Management. 2nd edn, Singular Publishing Group, a division of Thomson Learning, Inc., now Cengage: Albany, NY, USA, 2002.

10 Arvedson JC, Lefton-Greif MA (eds) Pediatric Videofluoroscopic Swallow Studies: A professional manual with Caregiver Guidelines. Communication Skill Builders, now Pearson: San Antonio, TX, USA, 1998.

11 Santos MT, Batista R, Previtali E, Ortega A, Nascimento O, Jardim J. Oral motor performance in spastic cerebral palsy individuals: are hydration and nutritional status associated? J Oral Pathol Med 2012; 41: 153-157.

12 Arvedson J, Rogers B, Buck G, Smart P, Msall M. Silent aspiration prominent in children with dysphagia. Int J Ped Otorhinolaryngol 1994; 28: 173-181.

13 Rogers B, Arvedson J, Buck G, Smart P, Msall M. Hypoxemia during oral feeding of children with severe cerebral palsy. Dysphagia 1994; 9: 69-74.

14 Sitton M, Arvedson J, Visotcky A, Braun N, Kerschner J, Tarima S et al. Fiberoptic endoscopic evaluation of Swallowing in children: feeding outcomes related to diagnostic groups and endoscopic findings. Int J Pediatr Otorhinolaryngol 2011; 75: $1024-1031$

15 da Silva AP, Lubianca Neto JF, Santoro PP. Comparison between videofluoroscopy and endoscopic evaluation of swallowing for the diagnosis of dysphagia in children. Otolaryngol Head Neck Surg 2010; 143: 204-209.

16 Kelly AM, Leslie P, Beale T, Payten C, Drinnan MJ. Fibreoptic endoscopic evaluation of swallowing and videofluoroscopy: does examination type influence perception of pharyngeal residue severity? Clin Otolaryngol 2006; 31: 425-432.

17 Arvedson J, Clark H, Lazarus C, Schooling T, Frymark T. Evidence-based systematic review (EBSR): the effects of oral motor intervention on feeding and swallowing in preterm infants. Am J Speech Lang Pathol 2010; 19: 321-340.
18 Bingham PM, Ashikaga T, Abbasi S. Prospective study of non-nutritive sucking and feeding skills in premature infants. Arch Dis Child Fetal Neonatal Ed 2010; 95: F194-F200.

19 Pinelli J, Symington A. Non-nutritive sucking for promoting physiologic stability and nutrition in preterm infants. Cochrane Database Syst Rev 2005; 4 CD001071.

20 Rogers BT, Arvedson J, Msall M, Demerath RR. Hypoxemia during oral feeding of children with severe cerebral palsy. Dev Med Child Neurol 1993; 35: 3-10.

21 Snider L, Majnemer A, Darsaklis V. Feeding interventions for children with cerebral palsy: a review of the evidence. Phys Occup Ther Pediatr 2011; 31: 58-77.

22 Morgan AT, Dodrill P, Ward EC. Interventions for oropharyngeal dysphagia in children with neurological impairment. Cochrane Database Syst Rev 2012; 10 CD009456.

23 Rogers B. Feeding method and health outcomes of children with cerebral palsy. J Pediatr 2004; 145: S28-S32.

24 Scianni A, Butler JM, Ada L, Teixeria-Salmela LF. Muscle strengthening is not effective in children and adolescents with cerebral palsy: a systematic review. Austr J Physiother 2009; 55: 81-87.

25 Gisel E. Interventions and outcomes for children with dysphagia. Dev Disabil Res Rev 2008; 14: 165-173.

26 Gisel EG. Effect of oral sensorimotor treatment on measures of growth and efficiency of eating in the moderately eating-impaired child with cerebral palsy. Dysphagia 1996; 11: 48-58.

27 Gisel EG, Applegate-Ferrante T, Benson JE, Bosma JF. Effect of oral sensorimotor treatment on measures of growth, eating efficiency and aspiration in the dysphagic child with cerebral palsy. Dev Med Child Neurol 1995; 37: 528-543.

28 Arvedson J, Clark H, Lazarus C, Schooling T, Frymark T. The effects of oral-motor exercises on swallowing in children: an evidence-based systematic review. Dev Med Child Neurol 2010; 52: 1000-1013.

29 Croft RD. What consistency of food is best for children with cerebral palsy who cannot chew? Arch Dis Child 1992; 67: 269-271.

30 Morton RE, Bonas R, Fourie B, Minford J. Videofluoroscopy in the assessment of feeding disorders of children with neurological problems. Dev Med Child Neurol 1993; 35: 388-395.

31 Banerdt B, Bricker D. A training program for selected self-feeding skills for the motorically impaired. AAESPH Review 1978; 3: 222-229.

32 Pinnington L, Hegarty J. Effects of consistent food presentation on efficiency of eating and nutritive value of food consumed by children with severe neurological impairment. Dysphagia 1999; 14: 17-26.

33 Pinnington L, Hegarty J. Effects of consistent food presentation on oral-motor skill acquisition in children with severe neurological impairment. Dysphagia 2000; 15 213-223.

34 Clark H, Lazarus C, Arvedson J, Schooling T, Frymark T. Evidence-based systematic review: effects of neuromuscular electrical stimulation on swallowing and neural activation. Am J Speech Lang Pathol 2009; 18: 361-375.

35 Christiaanse ME, Mabe B, Russell G, Simeone TL, Fortunato J, Rubin B. Neuromuscular electrical stimulation is no more effective than usual care for the treatment of primary dysphagia in children. Pediatr Pulmonol 2011; 46 $559-565$

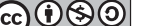

This work is licensed under a Creative Commons AttributionNonCommercial-ShareAlike 3.0 Unported License. To view a copy of this license, visit http://creativecommons.org/licenses/by-nc-sa/3.0/ 